\title{
UNLOCKING THE FACTS BEHIND NURSING STUDENT CLINICAL PRACTICES: CHALLENGES DURING THE COVID-19 OUTBREAK
}

\author{
by \\ Ira Kusumawaty ${ }^{1}$, Yunike ${ }^{2}$, Devi Mediarti ${ }^{3}$, Yeni Elviani ${ }^{4}$ \\ ${ }^{1}$ Department of Mental Health Nursing, Politeknik Kesehatan Kemenkes Palembang,Indonesia \\ ${ }^{2,4}$ Department of pediatric Nursing, Politeknik Kesehatan Kemenkes Palembang,Indonesia \\ ${ }^{3}$ Department of Medical Surgical Nursing, Politeknik Kesehatan Kemenkes Palembang, Indonesia \\ Email: irakusumawaty@ poltekkespalembang.ac.id
}

\begin{tabular}{l}
\hline \hline Article Info \\
\hline Article history: \\
Received Nov 18, 2021 \\
Revised Dec 25, 2021 \\
Accepted Jan 29, 2022
\end{tabular}

Keywords:

Clinical practice

Nursing students

Covid-19 Pandemic

\begin{abstract}
The Covid-19 pandemic increases the complexity of implementing nursing clinic practices fluctuating. Clinical-stage learning outcomes are strongly influenced by online learning methods at the academic stage which preparing students' knowledge, skills, and attitudes before treating patients positively. In fact, preparation in academic stage is feared, because it can affect the formation of student professionalism. Many studies have revealed students' problems during clinical education, but information relating to student experience during clinical nursing practice is still very limited. This research aims to identify and explore the experience of nursing students in caring for Covid-19 patients during the nursing clinic. Qualitative research with phenomenological approaches and data collection using in-depth interviews have been implemented in this study. Participants are nursing students who have participated in nursing clinic practices during the Covid-19 pandemic, numbering 14 participants. Participants 'exposure was done with purposive sampling techniques. Researchers are research instruments using in-depth interview guidelines and voice recording devices. Trustworthiness efforts are made by conducting peer debriefing and member checking. The data were analyzed with Colaizzi's method and resulted in three main themes: gaining valuable experience during treatment, as a role model, and empathy for patients.
\end{abstract}

This is an open access article under the CC BY-SA license.

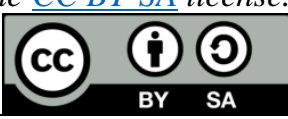

Corresponding Author:

Ira Kusumawaty,

Department of Mental Health Nursing, Politeknik Kesehatan Kemenkes Palembang, Indonesia

Email: irakusumawaty@poltekkespalembang.ac.id

\section{INTRODUCTION}

The establishment of professional conduct of nurses should begin in the order of academic education, which continues learning in the clinical demand. Learning at the academic stage discusses the theory and skills learned in a laboratory setting. At this stage, students are prepared to have knowledge, skills, and attitudes before being parachuted into the clinical learning stage[1]. The condition of the Covid-19 pandemic resulted in the implementation of academic stage learning using online methods[2]. However, this change in learning methods can result in students' lack of readiness and confidence in carrying out procedural [3] and the success of clinical-stage learning. It is strongly correlated with the academic stage learning process[4]. Some research suggests that some modifications have been made regarding the clinical learning of nursing students[5]. Online learning, recorded simulations, as well as 
learning many procedural skills through video have been widely adopted by some educational institutions. This is done to modify the implementation of student learning to achieve competence in accordance with expectations.

Professional nursing education realized through the clinical learning process aims so that students have the ability to solve real problems in the clinic. Clinical practice gives students the opportunity to be confronted with clinical issues, health care conditions, and actual patients[6]. However, the education of nursing professionals requires faceto-face learning because those who will receive services are human beings who can provide a diverse response to nursing services. Communication, empathy, caring as critical values in nursing services should be intensively trained[6]. However, the condition of the Covid-19 pandemic also provides limitations in the implementation of clinical learning due to the implementation of health protocols that must be adhered to.

The impact of the Covid-19 pandemic on health workers greatly influences the clinical learning process because it can increase anxiety levels and interfere with psychological conditions, including among nurses. (Spoorthy, Pratapa, \& Mahant, 2020). Nurses interact with Covid-19 directly, implies a high risk of nurses contracting Covid-19. Nevertheless, clinical nurses are role models for nursing students[7]. The success of clinical learning is highly dependent on external factors such as the environment and the clinical supervisor[8] and internal factors such as stress levels, confidence and student self-readiness [9],[10]. The formation of empathy affects the professionalism of nurses[1], and the majority is studied in clinical learning settings[11],[12] as it can only be shown when caring for patients. In general, academic hospitals have imposed the same policy in dealing with the clinic guidance process during pandemics. Some of the research results related to nursing clinic education has been carried out, but the availability of information about the student experience during the practice of nursing clinic in limited compassion. By exploring the experience during nursing clinical practice during pandemic times, it will help develop interventions in reducing the challenges faced.

\section{RESEARCH METHOD}

This qualitative research uses a phenomenological approach, to identify and explore the experience of nursing students in running nursing clinic practices during the Covid-19 pandemic. The focus of research attention is on the depth and quality of the information explored as well as the amount of information from the research subject.[13] Researcher role as an instrument or tool of a study serves to focus on the source, collection, quality of data, analysis and infer the results of its findings[ 14] who treats Covid-19 patients. Data collection techniques are conducted interviews and observations. Participants 'presentation was done by applying purposive sampling techniques. This study involved 14 fourth semester students who had completed nursing clinic practices in five hospitals of South Sumatra Province, the period April-July 2021, the Covid 19 pandemic period, were in good health and willing to engage in the study. research. Each nursing student informant is coded P1-P14. In-depth interview guides are used during the in-depth interview process, making participant experience points and continuing to be developed based on the responses given by informants. The interview results were recorded using a tape recorder and made transcripts, then the transcripts were analyzed using Colaizzi's method to formulate categories and themes. Stage analysis method Colaizzi analysis is done through several stages, namely repeatedly listening to the results, pile up transcript of the interview and subsequently collected, transcripts read repeatedly until obtaining significant and underlined main content, significant statements described perfectly, performing decryption validation through member checking, integrating themes in the narrative descriptive [15]. Ethics applied with the statement of approval to informed consent submitted, based on volunteerism and the existence of guarantees of confidentiality of information submitted and not will affect the assessment of the course. In order for confidentiality to be maintained, participants use pseudonyms with initial names and guarantee that information is submitted only for research purposes. Thefact that the review of research ethics has been obtained from the Health Research Ethics Committee of Palembang Health Polytechnic.

\section{RESULTS AND ANALYSIS}

\section{a. RESULT}

Based on the interview results, it is known that the age of the informant is in the age range of 18-19 years, 2 informants are male and 12 female informants. Six participants were come from the city of Palembang and others from outside the city of Palembang in the rural area. The in-depth interview process is conducted by the researcher in a place that has been agreed with participants. Furthermore, based on the results of the study, obtained three main themes, including: applying valuable experience during care (interacting with patients, applying theory in providing services), clinical nurses as role models (learn from senior nurses, and mimicking the way senior nurses communicate), and the challenges of building empathy for patients (restrictive health protocols, prohibitions on giving touch, and limiting time to interacting). With patients). 
International Journal of Social Science (IJSS)

Vol.1 Issue.5 February 2022, pp: 845-852

ISSN: 2798-3463 (Printed) | 2798-4079 (Online)

Main theme formation table

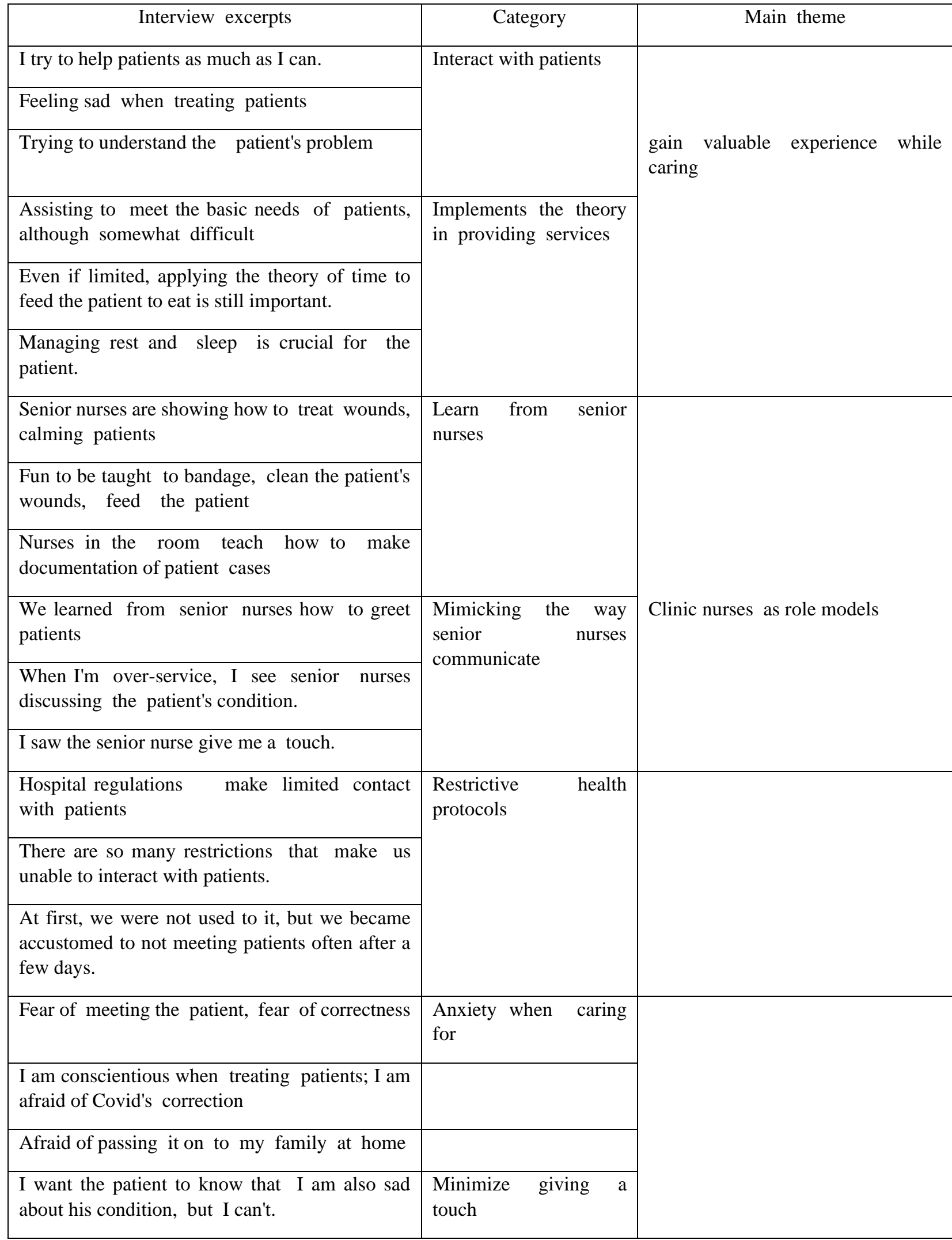




\begin{tabular}{|l|l|l|}
\hline $\begin{array}{l}\text { I'm used to touching patients when } \\
\text { communicating, but if this covid can't }\end{array}$ & \\
\cline { 1 - 2 } pe wants to touch the patient's hand so that the \\
patient can be calmer.
\end{tabular}

\section{b. Analysis}

The following analysis is presented based on three main theme formulations resulting from an in-depth exploration of research participants.

1. Gain valuable experience while caring for

This theme is formulated based on two categories of interview results, including interacting with patients and preparing theories in providing services. Understanding patient problems becomes an essential dimension in the condition of the Covid-19 pandemic becomes the first and unforgettable experience for participants throughout their lives, making it very valuable and challenging. Pandemic states have implications for the demands of improved ability to care for patients, as many components must be well anticipated for transmission to be prevented and minimized.[12] According to Maslow's theory, in helping patients meet basic human needs, participants must take care of themselves by adhering to health protocols, something that was never done before a pandemic. Caring for patients in a state of sadness becomes a scene that participants often face. Not infrequently, sadness envelops participants when treating isolated patients because no family members are accompanying them. The most pleasant moment for participants was when the patient received a patient swab result that turned negative[16], which indicated the patient's hospitalization period had ended and no longer tested positive for Covid-19. Exposure to Covid-19 is stress for patients, and participants can feel the patient's condition based on the information conveyed, which is referred to as empathy. Participants' desire to touch patients as a form of the heart becomes inhibited due to limited physical contact with the patient [15].

Behind the desire to convey empathy, participants also felt anxiety. Participants were faced with new problems that had never been experienced before. Fear, worry, and stress are normal responses to perceived threats when facing uncertainty or the unknown. Coupled with the fear of contracting the coronavirus, pandemics can be psychosocial stressors for every layer of society[17]. It is realized that health workers must adapt extra hard in providing a complete service with the threat of Covid-19 that continues to threaten. There was concern that they would bring the virus home after their work.[18],[19]. Other valuable participant experiences include participants taking turns checking the condition of Covid-19 patients, communicating with fellow nurses doctors, and becoming friends for patients in isolation rooms due to exposure to Covid-19[20]. Moreover, treating elderly patients who have difficulty doing activities alone. Caring for Covid-19 patients is often haunted by the fear of contracting it, but the condition becomes calmer after knowing the various facilities, cooperation, and attention given to health workers[18].

Understanding the patient's condition comprehensively is a frame of mind for nurses in making clinical decisions because accurate and appropriate clinical findings will optimize the health status of the client, thereby accelerating healing and recovery[21]. Some valuable experience when encountering positive patients is Covid-19 has been declared cured or sad due to cases that are not handled[15], [22]. Treating patients while paying attention to health protocols adds to participants' insight because participants never studied it at the academic stage[17],[20].

2. Clinic nurses as role models

Nursing education includes two stages: the academic stage and the clinical stage, a single entity. Teaching the professional background in the clinic is the core of nursing education that needs to get more institutional attention and still use the apprenticeship method. Conditions of nonconformity about the behavioral gap between the academic stage 
International Journal of Social Science (IJSS)

Vol.1 Issue.5 February 2022, pp: 845-852

ISSN: 2798-3463 (Printed) | 2798-4079 (Online)

DOI: https://doi.org/10.53625/ijss.v1i5.1220

and the behavior observed by students at the clinical stage lead to learning skills in the clinic requiring the facilitation of a clinical supervisor[23],[24].

Clinical nurses, positioned as a supervisor nursing student, becomes a role model to teach behavioral attitudes, skills, and knowledge. Role models as an integral part of the behavioral learning process, as students learn from figures observed in the daily learning process[3], [20],[25]. The information observed from the model (clinic guide) will then be re-retensiated by the student, processed in memory, and motivated to perform behavior according to the observed model [23]. During the Covid-19 pandemic, participants recognized that the role of clinical nurses was critical to becoming role models. Participants do not prepare to provide services in pandemic situations. Due to face-to-face learning restitution, nursing skills procedures are only obtained at the academic stage through online learning methods.

At the clinical learning stage, nursing students make observations and follows the interaction of the clinic supervisor with his patients and others so that the role of the clinic supervisor as a good role model is needed. A good role model has three criteria: clinical competence, teaching skills, and personal quality[6], [12], and competence are closely related to teaching skills. Students with real learning situations involving patients strongly expect the direction of the clinical supervisor [19] [26] to confirm knowledge and assess their actions to the patient.

Role modeling in the education of the nursing profession in the clinic, such as qualitative studies conducted on role modeling teaching the skills of the nurse's relationship with her patient, should be done in a varied way and is highly dependent on role. Sharing the experience of a clinical tutor is an effective way to increase students' understanding of relationship skills [6], [10],[22]. Not to create barriers for student competency development, institutions need to identify and address poor or negative role models immediately, even causing confusion and demotivation for students[5],[6].

The competencies taught at the professional level of education focus on skills or skills and professionalism. They will be obtained after students are exposed for a long time during the educational process[3],[29]. Clinics need to understand this and act as role models as professional nurses in the learning process integrated with the service process. In teaching professionalism, role modeling in the early stages of clinical contact affects the initiation of professionalism, while critical reflection is essential in the initiation of professionalism.

In undergoing nursing clinic practice, participants cannot escape the anxiety that arises from changing conditions. Not optimal learning skills at the academic stage only implemented online affect participants' confidence when treating patients[3],[30]. Anxiety is a fear of something caused by the anticipation of danger and is a signal that helps individuals prepare for action in the face of the threat. The influence of demands competition that occurs in the life of individuals can have an impact on physical health and psychology. One of the psychological effects is anxiety This anxiety appears in all aspects of health and social care and is experienced by all nursing team members. In clinical learning, participants experienced anxiety due to the limitations of implementing learning methods carried out online. This condition resulted in the significant expectation of participants to get maximum clinical guidance, meanwhile. Clinical supervisors still should serve patients so that this deed becomes an obstacle in the clinical learning process.

3. It builds empathy for patients

When treating, this theme is based on anxiety, minimizing giving touch and time to interact with patients. Empathy is the emotional ability to understand the feelings of others so that they can see a problem from the other person's point of view. This concept is a form of emotional intelligence characterized by the ability to listen to a speech, accept viewpoints, feel the feelings of others based on changes in expression, tone of speech, and body language [5], [33], [34]. Empathy is the behavior of being conscious and reacting mentally and emotionally to others, feeling sympathy and concern for others, especially in others who are suffering by putting themselves in that other person's position so that others seem to be a part of him.

A deep feeling of empathy arises because the patient is treated alone in the absence of family and the presence of the patient who died. Some respondents experienced an extraordinary experience while treating patients; for example, they were happy if patients who had tested positive for Covid-19 could recover. Nurses' empathy in the inpatient room significantly impacts improving the quality of nursing services to patients. The results stated that Covid19 causes psychosocial effects of anxiety in nurses. Nurses, especially those who handle Covid-19 patients, have concerns or anxiety in the form of fear of contracting the coronavirus, fear if they transmit the virus to family or people nearby, to fear of being shunned by the social environment. The presence of this pressure can affect the willingness and sincerity of nurses in work can even affect the way they communicate[29],[36]. So, it is always expected to instill the values of professionalism. The role of nurses is needed to be at the forefront of responding to and caring for Covid19 patients. Nurses need to develop various skills in dealing with these conditions, ranging from science skills to professional attitudes.

Stress and anxiety are reactions to threatening and unexpected situations such as the coronavirus pandemic. Health care workers are the most vulnerable to this. Stress-related reactions include changes in concentration, 
irritability, anxiety, difficulty sleeping, reduced productivity, and interpersonal conflicts; in subsequent cases, they will experience more severe psychiatric conditions, separation from family, abnormal situations, increased exposure, fear of COVID-19 transmission, feelings of failure in dealing with poor prognosis, inadequate technical facilities, PPE, tools, and equipment, to help care for patients. Other challenges faced while undergoing clinical practice is when communicating with the patient's family. Participants exemplified when patients who have symptoms are pretty severe and should be referred, but because of the room's limitations, the treatment process must be empty.

\section{CONCLUSION}

Nursing clinical practices during the Covid-19 pandemic provide various opportunities and challenges for nursing students to be more critical in delivering services by modifying the situation following health protocols. Must be obeyed. Both internal and external factors can contribute to clinical skills, empathy, and professionalism by learning clinical nurses' appearance as role models. Increasing the knowledge and skills to care for Covid-19 patients will positively impact overcoming anxiety and problems that often occur in treating Covid-19 patients. Preparing nursing students' learning about pandemic conditions early on the academic stage should be integrated into the curriculum to better prepare students to deal with various situations. Service.

\section{ACKNOWLEDGEMENTS}

Our thanks go to the participants for their dedication to telling their experiences and the management of Palembang Health Polytechnic, who have supported the implementation of this study.

\section{REFERENCES}

[1] A. Dyar, T. Stenfors, H. Lachmann, and A. Kiessling, "What about the supervisor? Clinical supervisors' role in student nurses' peer learning: A phenomenographic study," Med. Educ. , vol. 55, no. 6, pp. 713-723, 2021, doi: 10.1111/medu. 14436.

[2] D. Terry and B. Peck, "Academic and clinical performance among nursing students: What's grit go to do with it?," Nurse Educ. Today, vol. 88, no. September 2019, p. 104371, 2020, doi: 10.1016/j.nedt.2020.104371.

[3] A.M. Tuomikoski et al. , "How mentoring education affects nurse mentors' competence in mentoring students during clinical practice - A quasi-experimental study'," Scand. J. Caring Sci. , vol. 34, no. 1, pp. 230-238, 2020, doi: $10.1111 /$ scs.12728.

[4] C. Ossenberg, M. Mitchell, and A. Henderson, "Impact of a work-based feedback intervention on student performance during clinical placements in acute-care healthcare settings: A quasi-experimental protocol for the REMARK programme," BMJ Open, vol. 10, no. 6, 2020, doi: 10.1136/bmjopen-2019-034945.

[5] J. Subke, C. Downing, and I. Kearns, "Practices of caring for nursing students: A clinical learning environment," Int. J. Nurs. Sci. , vol. 7, no. 2, pp. 214-219, 2020, doi: 10.1016/j.ijnss.2020.03.005.

[6] P. Hagqvist, A. Oikarainen, A.M. Tuomikoski, J. Juntunen, and K. Mikkonen, "Clinical mentors' experiences of their intercultural communication competence in mentoring culturally and linguistically diverse nursing students: A qualitative study," Nurse Educ. Today, vol. 87, no. January, p. 104348, 2020, doi: 10.1016/j.nedt.2020.104348.

[7] A.M. Kaihlanen, M. Elovainio, E. Haavisto, L. Salminen, and T. Sinervo, "Final clinical practicum, transition experience and turnover intentions among newly graduated nurses: A cross sectional study," Nurse Educ. Today, vol. 84, no. May 2019, p. 104245, 2020, doi: 10.1016/j.nedt.2019.104245.

[8] E. N. Opoku, L. Van Niekerk, and L. A. Jacobs-Nzuzi Khuabi, "Exploring the factors that affect new graduates' transition from students to health professionals: A systematic integrative review protocol," BMJ Open, vol. 10, no. 8, pp. 1-5, 2020, doi: 10.1136/bmjopen-2019-033734.

[9] M. Sánchez de Miguel, A. Orkaizagirre-Gómara, J. Ortiz de Elguea, A. Izagirre Otaegi, and A. Ortiz de ElgueaOviedo, "Factors contributing to stress in clinical practices: A proposed structural equation model," Nurs. Open, vol. 7, no. 1, pp. 364-375, 2020, doi: 10.1002/nop2.397.

[10] A. ŞentÜrk Erenel et al. , "Effect of Scenario-Based Simulation Training on the Obstetrics and Gynecology Nursing Clinical Practicum," J. Nurs. Res., vol. 29, no. 2, p. e142, 2021, doi: 10.1097/jnr.0000000000000417.

[11] J. Singh and B. Matthees, "Facilitating interprofessional education in an online environment during the COVID19 pandemic: A mixed method study," Healthc. , vol. 9, no. 5, 2021, doi: 10.3390/healthcare9050567.

[12] D. Ulenaers, J. Grosemans, W. Schrooten, and J. Bergs, "Clinical placement experience of nursing students during the COVID-19 pandemic: A cross-sectional study," Nurse Educ. Today, vol. 99, no. August 2020, p. 104746, 2021, doi: 10.1016/j.nedt.2021.104746.

[13] J. W. Craswell, Educationel Research. 2012.

[14] John W. Creswell, Research Desaign qualitative, quantitative, and mixed methods Approaches. 2002.

[15] M. . Spoorthy, S. . Pratapa, and M. Supriya, "Since January 2020 Elsevier has created a COVID-19 resource 
International Journal of Social Science (IJSS)

Vol.1 Issue.5 February 2022, pp: 845-852

ISSN: 2798-3463 (Printed) | 2798-4079 (Online)

DOI: https://doi.org/10.53625/ijss.v1i5.1220

centre with free information in English and Mandarin on the novel coronavirus COVID- 19. The COVID-19 resource centre is hosted on Elsevier Connect, the company 's public news and information," Asian J. Psychiatr. , no. January, 2020.

[16] M. Gordon, T. Kagalwala, K. Rezk, C. Rawlingson, M. I. Ahmed, and A. Guleri, "Rapid systematic review of neonatal COVID-19 including a case of presumed vertical transmission," BMJ Paediatr. Open, vol. 4, no. 1, 2020, doi: 10.1136/bmjpo-2020-000718.

[17] A. Khanam, S. A. Dar, Z. A. Wani, N. N. Shah, I. Haq, and S. Kousar, "Healthcare Providers on the Frontline: A Quantitative Investigation of the Stress and Recent Onset Psychological Impact of Delivering Health Care Services During COVID-19 in Kashmir," Indian J. Psychol. Med. , vol. 42, no. 4, pp. 359-367, 2020, doi: $10.1177 / 0253717620933985$.

[18] M. F. Chersich et al. , "Covid-19 in Africa: Care and protection for frontline healthcare workers," Global. Health, vol. 16, no. 1, pp. 1-6, 2020, doi: 10.1186/s12992-020-00574-3.

[19] G. Intinarelli, L.M. Wagner, B. Burgel, R. Andersen, and C. L. Gilliss, "Nurse practitioner students as an essential workforce: The lessons of coronavirus disease 2019," Nurs. Outlook, vol. 69, no. 3, pp. 333-339, 2021, doi: 10.1016/j.outlook.2020.12.002.

[20] I. Taylor et al. , "The self-assessment of clinical competence and the need for further training: A cross-sectional survey of advanced practice nursing students," J. Clin. Nurs., vol. 29, no. 3-4, pp. 545-555, 2020, doi: 10.1111/jocn.15095.

[21] Potter, Patricia Ann; Perry, Potter \& Perry's fundamentals of nursing. 2013.

[22] D. O. Himes and P. K. Ravert, "Situated Peer Coaching and Unfolding Cases in the Fundamentals Skills Laboratory," Int. J. Nurs. Educ. Scholarsh. , vol. 9, no. 1, 2020, doi: 10.1515/1548-923X.2335.

[23] M. R. Kauth, G. Sullivan, J. Cully, and D. Blevins, "Facilitating Practice Changes in Mental Health Clinics: A Guide for Implementation Development in Health Care Systems," Psychol. Serv. , vol. 8, no. 1, pp. 36-47, 2011, doi: $10.1037 / \mathrm{a} 0022250$.

[24] M.M. Davis, S. Howk, M. Spurlock, P.B. McGinnis, D. J. Cohen, and L. J. Fagnan, "A qualitative study of clinic and community member perspectives on intervention toolkits: 'unless the toolkit is used it won't help solve the problem,"' BMC Health Services Research, vol. 17, no. 1. 2017, doi: 10.1186/s12913-017-2413-y.

[25] D. Comparcini, G. Cicolini, V. Simonetti, K. Mikkonen, M. Kääriäinen, and M. Tomietto, "Developing mentorship in clinical practice: Psychometrics properties of the Mentors' Competence Instrument," Nurse Educ. Pract. , vol. 43, no. January, p. 102713, 2020, doi: 10.1016/j.nepr.2020.102713.

[26] N. Fogg et al. , "Transitioning from direct care to virtual clinical experiences during the COVID-19 pandemic," J. Prof. Nurs. , vol. 36, no. 6, pp. 685-691, 2020, doi: 10.1016/j.profnurs.2020.09.012.

[27] A. F. Bolina, E. Bomfim, and L.C. Lopes-Júnior, "Frontline Nursing Care: The COVID-19 Pandemic and the Brazilian Health System," SAGE Open Nurs. , vol. 6, 2020, doi: 10.1177/2377960820963771.

[28] M. Krivokapic, "Imitative learning: The teacher as a role model," Educ. Self Dev. , vol. 13, no. 4, pp. 11-19, 2018, doi: 10.26907/esd13.4.02.

[29] L.M. Gorman and R. Anwar, Neeb's Fundamentals of Mental Health Nursing. 2014.

[30] S. O'Connor, S. Jolliffe, E. Stanmore, L. Renwick, and R. Booth, "Social media in nursing and midwifery education: A mixed study systematic review," J. Adv. Nurs., vol. 74, no. 10, pp. 2273-2289, 2018, doi: 10.1111/jan.13799.

[31] M.C. Townsend, "Psychiatric_MentConcepts of Care in Evidence-Based Practice-F.A. Davis Company (2014)." p. 1088, 2014.

[32] N. Greenberg, M. Docherty, S. Gnanapragasam, and S. Wessely, "Managing mental health challenges faced by healthcare workers during covid-19 pandemic," $B M J$, vol. 368, no. March, pp. 1-4, 2020, doi: 10.1136/bmj.m1211.

[33] H. Sun et al. , "Correlation between emotional intelligence and negative emotions of front-line nurses during the COVID-19 epidemic: A cross-sectional study," J. Clin. Nurs. , vol. 30, no. 3-4, pp. 385-396, 2021, doi: 10.1111/jocn.15548.

[34] C. Romo-Barrientos et al. , "Anxiety levels among health sciences students during their first visit to the dissection room," BMC Med. Educ. , vol. 20, no. 1, pp. 1-7, 2020, doi: 10.1186/s12909-020-02027-2.

[35] S. Prot et al. , "Long-Term Relations Among Prosocial-Media Use, Empathy, and Prosocial Behavior," Psychol. Sci. , vol. 25, no. 2, pp. 358-368, 2014, doi: 10.1177/0956797613503854.

[36] J. Tomlin, B. Dalgleish-Warburton, and G. Lamph, "Psychosocial Support for Healthcare Workers During the COVID-19 Pandemic," Front. Psychol., vol. 11, no. August, pp. 1-7, 2020, doi: 10.3389/fpsyg.2020.01960. 
[37] Sastra, A. I., Anwar, Od. M., \& Ibrahim, M. N. (2017). THE CONCEPT OF PANGAWINAN IN THE MUSIC PERFORMANCE OF TALEMPONG RENJEANG ANAM SALABUHANIN LUHAK NAN TIGO

MINANGKABAU. Journal of Nusantara Studies (JONUS), 2(2), 333.

https://doi.org/10.24200/jonus.vol2iss2pp333-347 